\section{Projeto de extensão de Yoga: auxiliando na formação profissional e acadêmica do estu- dante de graduação em Educação Física}

\section{Yoga Project: Contributing to academic and professional formation of student of Physi- cal Education}

\author{
Ana Cláudia Gomes de Amorim Pinto ${ }^{1}$ \\ Silvia Deutsch ${ }^{1}$ \\ Gabriela Grimaldi ${ }^{1}$ \\ Luis Felipe Manfroni ${ }^{1}$ \\ Déborah Oliveira $^{1}$ \\ Marcelo Garuffí2
}

\section{Resumo}

O programa de extensão de Yoga realizado na UNESP - Rio Claro teve início em 2006 e é constituído por três grupos. As aulas são de 60 minutos de duração duas vezes por semana, focadas em trabalhar o corpo físico, com base nas posturas psicofísicas do Yoga, aliadas a exercícios respiratórios e de relaxamento. Procura através deste método proporcionar bem estar físico e mental favorecendo a manutenção e melhora de aspectos psicológicos dos alunos, que são predominantemente pessoas da universidade e da comunidade de Rio Claro. Resultados positivos foram obtidos nos estudos sobre motivação e estados de ânimo feitos com esses grupos. O programa possibilita ainda uma vivência pedagógica dos alunos do curso de Educação Física interessados nessa área e o desenvolvimento de projetos de pesquisa auxiliando na formação profissional e acadêmica do estudante de graduação.

\section{Palavras-chave}

Yoga; Qualidade de vida; Bem estar.

\begin{abstract}
The extension program of Yoga at UNESP - Rio Claro began in 2006 and constitutes of 3 classes that are 60 minutes long twice a week, focus in a physical work out, through Yoga psychophysical postures, along with breathing exercises and relaxation and seeks through this method to provide physical and mental well-being, favoring the maintenance and improvement of students' psychological aspects, which are predominantly people from the university and the community of Rio Claro. Positive results were obtained in studies on motivation and moods made with these groups. The program also allows an experience teaching students of Physical Education who are interesting in this area of study. It also allows the educational experience for students of physical education and the development of a lot research projects.
\end{abstract}

\section{Keywords}

Yoga; Quality of life; Well-being.
Rev Bras Ativ Fis Saúde p. 434-439 DOI: http://dx.doi.org/10.12820/2317. $1634.2012 \mathrm{v} 17 \mathrm{n} 5 \mathrm{p} 434$

1 UNESP - Universidade Estadual Paulista, Instituto de Biociências, Departamento de Educação Física, Laboratório de Comunicação Corporal Expressão e Música (LACCEM)

2 UNESP - Universidade Estadual Paulista Instituto de Biociências, Departamento de Educação Física, Laboratório de Atividade Física e Envelhecimento (LAFE) 


\section{INTRODUÇÃO}

Em seu aspecto mais antigo, o Yoga foi concebido como uma técnica para aumentar os poderes vitais. Esse aspecto foi desenvolvido e aperfeiçoado posteriormente pelo $\mathrm{Ha}$ tha Yoga com a introdução de práticas para controlar os efeitos e impactos da natureza ${ }^{1}$.

Preocupações e pensamentos fazem com que a mente esteja em constante agitação, sendo esta a responsável pelas transfigurações dos objetos percebidos, ou seja, aquilo que o objeto realmente toma forma e cores através dos sentidos, da imaginação, da memória e das emoções. A mente é como uma onda contínua, tremulando em um lago e que jamais ficará parada como um espelho cristalino em seu estado próprio, a não ser que se detenham as águas afluentes, turbulentas e perturbadoras da substância translúcida, ou seja, deter as impressões sensórias vindas do exterior e também os impulsos internos como as recordações, as pressões emocionais e as instigações da imaginação ${ }^{2}$.

A relação entre mente e corpo parece ser a maior responsável tanto pelo equilíbrio quanto pelo desequilíbrio dos indivíduos. Nessa perspectiva o Hatha-Yoga é uma vertente do Yoga que busca desenvolver o potencial do corpo estabelecendo sua integração com a mente, atenuando, desta forma problemas físicos e emocionais ${ }^{3}$.

Neste estudo será apresentado um relato do projeto de Extensão de Yoga, desenvolvido na UNESP - Universidade Estadual Paulista "Julio de Mesquita Filho" como uma forma de intervenção à comunidade, proporcionando os benefícios advindos desta prática, bem como na criação de um ambiente propício ao ensino didático-pedagógico que possibilita a formação de alunos de graduação em educação física e aprimoramento à profissionais da área.

\section{YOGA COMO OPÇÃO DE ATIVIDADE FÍSICA}

Em todas as técnicas deste sistema o praticante busca eliminar sua agitação e ter um domínio harmônico de si mesmo. Para dominar o corpo, são praticadas posturas, os asanas, nas quais se deve sempre manter a estabilidade e o conforto ${ }^{4}$. Já para dominar a respiração, são praticados os pranayamas, exercícios de controle respiratório que induzem ao equilíbrio respiratório até que se possa atingir pausas conscientes, confortáveis e prolongadas 4 .

Além da prática dos asanas serem realiados com fins espirituais, são também voltados para benefícios físicos como melhora de flexibilidade, coordenação neuromuscular, entre outras capacidades físicas e benefícios ${ }^{5}$.Já o controle respiratório, desenvolvido por meio dos pranayamas, estimula o sistema nervoso autônomo a inibir o sistema nervoso simpático e estimular o parassimpático, diminuindo a frequência cardíaca e relaxando músculos esqueléticos como um todo ${ }^{6}$.

Nesse sentido, a prática de Hatha-Yoga pode ser de extrema utilidade uma vez que o relaxamento que esta atividade proporciona demonstra efeito hipotensor, contribuindo, por exemplo, na redução dos níveis de estresse ${ }^{7}$.

Com este entendimento, em 2006, foi criado o "Projeto de Extensão de Yoga", realizado com o apoio do Departamento de Educação Física da UNESP - Universidade Estadual Paulista - Campus de Rio Claro. O quadro 1 apresenta o modelo lógico de funcionamento do projeto de extensão de Yoga.

Serão apresentadas algumas estratégias utilizadas, que tornaram possível o desenvolvimento do Yoga pautado nos três pilares básicos dentro da estrutura universitária: ensino, pesquisa e extensão. 
Quadro 1 - Modelo Lógico de Funcionamento do Programa

\begin{tabular}{|c|c|c|c|c|}
\hline INSUMOS & ATIVIDADES & PRODUTOS & RESULTADOS INICIAIS & $\begin{array}{l}\text { RESULTADOS INTER- } \\
\text { MEDIÁRIOS/LONGO } \\
\text { PRAZO }\end{array}$ \\
\hline $\begin{array}{l}\text { Recursos Materiais: } \\
\text { - Estrutura Física: } \\
\text { Instalações - sala es- } \\
\text { pecífica para a prática } \\
\text { com piso adequado e } \\
\text { aparelho de som. } \\
\text { - Materiais: Tapetes } \\
\text { de Yoga (mats), } \\
\text { blocos e faixas. } \\
\text { Instrumentos para } \\
\text { coleta de dados das } \\
\text { pesquisas. }\end{array}$ & $\begin{array}{l}\text { Projeto de extensão de Yoga } \\
\text { para comunidade: } \\
\text { - Aulas de yoga } \\
\text { Anamnese, prescrição, orien- } \\
\text { tação e acompanhamento. } \\
\text { - Formação de alunos de gra- } \\
\text { duação interessados no Yoga } \\
\text { Disciplina optativa intitulada: } \\
\text { Introdução ao Yoga. } \\
\text { Reuniões de laboratório. } \\
\text { Estágios. }\end{array}$ & $\begin{array}{l}\text { Na formação de alunos de } \\
\text { graduação interessados } \\
\text { na área: } \\
\text { - Acadêmicos capacitados: } \\
2 \text { bolsistas, } 3 \text { estagiários } \\
\text { voluntários; } \\
\text { - Disciplina de Introdução } \\
\text { ao Yoga em curso de } \\
\text { graduação de Educação } \\
\text { Física; } \\
\text { - Desenvolvimento de } \\
\text { pesquisas em diferentes } \\
\text { áreas correlatas a Yoga; } \\
\text { - Elaboração, apresen- } \\
\text { tação e publicação de } \\
\text { trabalhos científicos e } \\
\text { monografias; } \\
\text { - Projetos e Relatórios } \\
\text { anuais. }\end{array}$ & $\begin{array}{l}\text { Na formação de alunos } \\
\text { de graduação interessa- } \\
\text { dos na área: } \\
\text { - Despertar o interesse } \\
\text { pela área; } \\
\text {-Aquisição de conhe- } \\
\text { cimentos e habilidades } \\
\text { para prescrição, elabora- } \\
\text { ção e acompanhamento } \\
\text { das aulas de Yoga; } \\
\text { - Maior envolvimento } \\
\text { com o campo de conhe- } \\
\text { cimento do Yoga; } \\
\text { - Interesse no desenvol- } \\
\text { vimento de pesquisas; }\end{array}$ & $\begin{array}{l}\text { Quanto aos participan- } \\
\text { tes das aulas de Yoga } \\
\text { oferecidas pelo projeto: } \\
\text {-Qualidade de vida } \\
\text { dos participantes no } \\
\text { programa; } \\
\text { - Aderência a uma prá- } \\
\text { tica da atividade física } \\
\text { regular; } \\
\text { - Maior compreensão } \\
\text { dos benefícios ofere- } \\
\text { cidos por esse tipo de } \\
\text { atividade; } \\
\text { - Ampliação e aprofun- } \\
\text { damento de técnicas de } \\
\text { Yoga chegando ao co- } \\
\text { nhecimento de práticas } \\
\text { meditativas. }\end{array}$ \\
\hline
\end{tabular}

O Projeto de Extensão de Yoga possui atualmente três turmas, com cerca de 35 alunos cada, o que representa o atendimento aproximado de 117 pessoas no período de um ano, isto em virtude do período de inscrições ser realizado no início do ano letivo, abrangendo universitários e moradores da comunidade local. As aulas que ocorrem duas vezes por semana para cada uma das turmas, possuem duração de 60 minutos e são divididas em quatro etapas: aquecimento das articulações, sequência de posturas psicofísicas do Yoga (asanas), exercício de respiração (pranayama) e relaxamento final. A prática das aulas de Yoga tem como propósito promover uma ação terapêutica, proporcionando o bem-estar físico e mental dos alunos, atuando na melhora da qualidade de vida e da sociabilidade.

Para participar das aulas do Projeto de Yoga, é necessário que os alunos respondam, inicialmente, uma ficha de anamnese, que visa identificar possíveis proble- 
mas. Isto porque, grande parte dos alunos apresenta problemas físicos, incluindo problemas posturais, lesões articulares e dores, sendo estas às vezes crônicas. Também é frequente a constatação em nossos alunos de problemas de ordem psicológica/emocional, caracterizados por sintomas de estresse e ansiedade excessivos, depressão e insônia. Utiliza-se ainda um termo de consentimento livre e esclarecido e há a aprovação do comitê de ética em pesquisa, CE/UCS - 034/2012 Protocolo da Universidade Cruzeiro do Sul, reconhecida pela portaria ministerial n893, D.O.U. 25/06/1993.

O Projeto conta com a participação de um professor docente, dois estagiários bolsistas e três estagiários voluntários graduandos em Educação Física, os quais conseguem, por meio do estágio, conhecer e aprofundar os conceitos básicos de como é estruturada uma aula de Yoga, além de se envolver na modalidade oferecida e complementar conteúdos ensinados na disciplina de graduação "Introdução ao Yoga”, oferecida no curso de graduação em Educação Física nesta instituição. Além das aulas, é realizado ainda um grupo de estudos sobre Yoga, que ocorre quinzenalmente, com o objetivo de proporcionar o aprofundamento de temas e vinculá-los aos projetos de pesquisa desenvolvidos na área.

Deu-se início a estudos envolvendo os aspectos motivacionais relacionados à prática de yoga para o qual foi elaborado um instrumento online em forma de questionário; e foi desenvolvido também um estudo que verifica a possível interferência da prática de yoga nos estados de ânimo utilizando a Lista de Estados de Ânimo Reduzida e Ilustrada (LEA-RI) ${ }^{8}$. Ambos os estudos são feitos com os participantes usuários do projeto de extensão. Há resultados preliminares de ambas as pesquisas. Quanto aos aspectos motivacionais pudemos observar que a maior tendência de resultados de motivação para a prática de Yoga aponta para a busca e manutenção da saúde e equilíbrio nos aspectos físicos e psicológicos. Quanto aos estados de ânimo foi observada uma melhora dos estados positivos e diminuição dos negativos.

Do total de alunos que frequentam o Projeto, $88,2 \%$ são estudantes dos cursos de graduação da UNESP/Rio Claro, sendo que apenas 11,8\% são da comunidade local. A média geral das idades é de 24,9 anos; a média da idade das mulheres (que representam 83,76\% do total de alunos) é de 25,24 anos; e dos homens (que representam $16,24 \%$ do total de alunos) é de 24,57 anos.

Tem-se como meta do Projeto, a publicação dos resultados dos estudos desenvolvidos em revistas científicas e sua apresentação em eventos acadêmicos, e assim contribuir com a comunidade acadêmica, explicitando os benefícios provenientes da prática do Yoga e fornecendo informações importantes aos profissionais de saúde que estudam essa área.

Este Projeto além de oferecer suporte para o grupo de estudos sobre Yoga possibilita também o desenvolvimento e a participação dos professores e alunos em eventos técnico-científicos. Geraram cursos de atualização de curta duração (Técnicas de respiração com base no Yoga - VII Congresso Internacional de Educação Física e Motricidade Humana e XIII Simpósio Paulista de Educação Física), e ainda o Encontro de Yoga, voltado a estudantes, profissionais da saúde e estudiosos de outras áreas, que tenham interesse no tema. Este evento, que ocorre desde 2010 e sempre no segundo semestre, é organizado pelo grupo de estudos sobre Yoga, juntamente com os alunos da disciplina e visa, através de palestras e oficinas práticas, proporcionar o contato e o conhecimento de diferentes linhas e vertentes do Yoga. 
O quadro abaixo apresenta os principais trabalhos e estudos realizados, com o apoio do Projeto de Extensão e pelo Laboratório de Comunicação Corporal Expressão e Música (LACCEM).

Quadro 2 - Publicações, trabalhos e eventos desenvolvidos no Programa de Extensão de Yoga.

\begin{tabular}{|lccc|}
\hline Título & Tipo de trabalho & Autor & Ano \\
\hline $\begin{array}{l}\text { O efeito da meditação no com- } \\
\text { portamento social do praticante }\end{array}$ & Resumo em anais & Deutsch S. et al & 2006 \\
\hline $\begin{array}{l}\text { A influência do Hatha Yoga nos } \\
\text { estados de ânimo }\end{array}$ & Resumo em anais & Tanaka K. et al & 2006 \\
\hline I Encontro de Yoga - UNESP 2012 & Evento Acadêmico & Deutsch S. & 2010 \\
\hline Yoga na Universidade & Painel & Amorim ACGP. et al & 2011 \\
\hline Yoga - Projeto de extensão & Painel e Vídeo & Amorim ACGP. et al & 2011 \\
\hline $\begin{array}{l}\text { A influência do Hatha Yoga nos } \\
\text { estados de ânimo }\end{array}$ & Trabalho de conclusão & Tanaka K. et al & 2011 \\
\hline II Encontro de Yoga - UNESP 2012 & Evento Acadêmico & Deutsch S. & 2011 \\
\hline $\begin{array}{l}\text { O efeito da meditação no com- } \\
\text { portamento social do praticante }\end{array}$ & Artigo & Deutsch S. et al & 2012 \\
\hline III Encontro de Yoga - UNESP 2012 & Evento Acadêmico & Deutsch S. & 2012 \\
\hline
\end{tabular}

\section{CONSIDERAÇÕES FINAIS}

O Projeto de Extensão de Yoga atende indivíduos que procuraram a prática de Yoga por orientação médica e também por vontade própria. Temos obtido melhoras aparentes tanto nos componentes psicológicos quanto físicos desses praticantes. Através das observações dos professores e relatos verbais por parte dos alunos que participam do projeto, o Yoga como forma de terapia vem ajudando tanto na saúde como na qualidade de vida e ainda proporciona a oportunidade de interação social dos alunos. A alta frequência (aproximadamente $75 \%$ do total de alunos matriculados) controlada através de lista de chamada e a grande aderência e permanência dos participantes nas aulas (em função da regra de que a cada 3 faltas sem justificativa o aluno perde sua vaga) nos garante uma maior eficiência do Projeto de Extensão--

O projeto proporciona além de tudo a vivência pedagógica para alunos do curso de graduação em Educação Física como forma de aprimoramento profissional e possibilita o desenvolvimento de diversos estudos relacionados com o Yoga. É possível observar ainda um maior interesse dos mesmos, após a realização do estágio no projeto, em atuar neste campo de trabalho, tanto na área didática como na pesquisa.

Por fim, o projeto também visa divulgar a prática do Yoga como uma forma de atividade física a qual deve ser praticada de forma regular, a fim de que sejam alcançados os benefícios advindos desta prática para a saúde e bem-estar proporcionando uma melhor qualidade de vida em seus praticantes.

\section{Agradecimentos / Financiamento}

Laboratório de Comunicação Corporal, Expressão e Música; Pró-Reitoria de Extensão Universitária (PROEX-UNESP).

\section{Contribuição dos autores}

A primeira autora, Ana Cláudia Gomes de Amorim Pinto é responsável pela ela- 
boração e redação principal do artigo, juntamente com Silvia Deutsch, também coordenadora do Projeto de Extensão. Gabriela Grimaldi e Marcelo Garuffi contribuíram na redação, revisão e formatação do manuscrito. Luis Felipe Manforni e Déborah Oliveira contribuíram na revisão do manuscrito.

\section{REFERÊNCIAS}

1. Souto A. A Essência do Hatha Yoga - Hatha Pradipika - Gheranda Samhita - Goraksha Shataka. São Paulo: Phorte, 2009.

2. Zimmer HR. Filosofias da Índia. São Paulo: Palas Athena, 2003.

3. Feuerstein G. Uma visão profunda da Yoga: teoria e prática. São Paulo: Pensamento, 2006.

4. Taimni IK. A Ciência do Yoga. Brasília. Editora Teosófica, 1996.

5. Gharote ML. Técnicas de Yoga. São Paulo: Phorte, 2000.

6. Rodrigues MR, Silva ACRD ; Santaella DF et al. Considerações fisiológicas. In: Rodrigues MR (Org). Estudo sobre o Yoga. São Paulo: Phorte, 2006: 75-95.

7. Silva, GD. Curso básico de Yoga: teórico-pratico. São Paulo: Phorte, 2009.

8. Volp CM. LEA para populações diversas. Relatório Trienal apresentado a CPRT. Rio Claro, Brasil: UNESP, Instituto de Biociências, 2000.

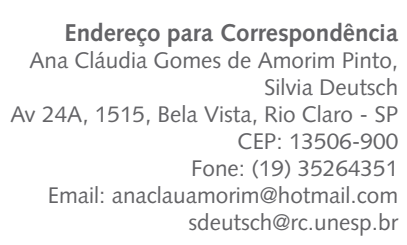

$$
\begin{array}{ll}
\text { Recebido } & 14 / 06 / 2012 \\
\text { Revisado } & 04 / 07 / 2012 \\
& 15 / 11 / 2012 \\
& 12 / 12 / 2012 \\
\text { Aprovado } & 15 / 01 / 2013
\end{array}
$$

